\title{
Conflitos socioambientais por água no Nordeste brasileiro: expropriações contemporâneas e lutas sociais no campo ${ }^{1}$
}

\author{
Sandra Maria Batista Silveira ${ }^{1}$ \\ https://orcid.org/0000-0003-0166-5664
}

\author{
Maria das Graças e Silva ${ }^{2}$
}

https://orcid.org/0000-0002-6583-831X

${ }^{1}$ Universidade Federal de Pernambuco, Departamento de Serviço Social, Recife, PE, Brasil

${ }^{2}$ Universidade Federal de Pernambuco, Departamento de Serviço Social, Programa de Pós-Graduação em Serviço Social, Recife, PE, Brasil

\section{Conflitos socioambientais por água no Nordeste brasileiro: expropriações contemporâneas e lutas sociais no campo}

Resumo: A mercantilização da água expressa de maneira inequívoca o agravamento das desigualdades sociais no campo, resultando no aumento dos conflitos que envolvem a posse, a propriedade e os usos da água pelas populações rurais. Este artigo tem como objetivo refletir sobre os conflitos por água na região do Nordeste brasileiro, problematizando-os à luz de suas determinações estruturais: a expansão do agronegócio e seus impactos sobre as populações do campo. Este resulta de uma ampla pesquisa bibliográfica, realizada em nível de doutorado, além da análise de documentos institucionais que versam sobre a temática. Assim, apreende-se que o acirramento dos conflitos por água na região está vinculado à apropriação privada da terra, estabelecendo-se o confronto entre classes e frações das classes fundamentais: de um lado, o agronegócio e de outro campo: ribeirinhos, quilombolas, pescadores(as), indígenas e pequenos agricultores, as quais estabelecem seu metabolismo social (FOSTER, 2005) em estreita dependência dos recursos naturais.

Palavras-chave: Conflitos por água. Expropriações contemporâneas. Nordeste brasileiro.

\section{Socio-environmental conflicts over water in the Northeast of Brazil: Contemporary expropriations} and social struggles in rural areas

Abstract: The commercialization of water expresses the aggravation of social inequalities in rural areas, increasing conflicts involving the possession, ownership, and use of water by the local population. This article discusses the conflicts over water conflicts in the Northeast of Brazil, considering the structural determinations around the issue: the expansion of agribusiness and its impacts on rural populations. The study conducts extensive bibliographic research, carried out during doctorate studies, in addition to the analysis of institutional documents around the theme. The intensification of water conflicts in the region is linked to the private appropriation of land, establishing the confrontation between classes and parts of the fundamental classes. On the one side is the agribusiness, and on the other riverine, quilombola, fishermen, indigenous, and small farmers, who establish their "social metabolism" (FOSTER, 2005) with close dependence on natural resources.

Keywords: Conflict over water. Contemporary expropriations. Northeast of Brazil.

Recebido em 01.10.2018. Aprovado em 20.11.2018. Revisado em 29.04.2019.

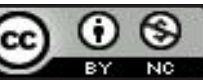

C O(s) Autor(es). 2019 Acesso Aberto Esta obra está licenciada sob os termos da Licença Creative Commons

Atribuição-NãoComercial 4.0 Internacional (https://creativecommons.org/licenses/by-nc/4.0/deed.pt_BR), que permite copiar, distribuir e reproduzir em qualquer meio, bem como adaptar, transformar e criar a partir deste material, desde que para fins não comerciais e que você forneça o devido crédito aos autores e a fonte, insira um link para a Licença Creative Commons e indique se mudanças foram feitas. 


\section{Introdução}

Nos dias atuais, a questão da água ${ }^{2}$ tem assumido centralidade nos debates políticos e acadêmicos, tanto no que diz respeito à sustentabilidade das estratégias de abastecimento humano e das políticas de saneamento básico, quanto aos usos indispensáveis nos processos produtivos. Também vêm assumindo posição de destaque nesse debate os variados conflitos socioambientais relacionados à água, que expõem aos maiores riscos a população mais pobre das áreas urbanas e rurais. A água é um requisito indispensável à vida e um recurso fundamental na produção de alimentos para as populações humanas e para todas as espécies. No entanto, o abastecimento hídrico e os problemas a ele relacionados mantêm uma vinculação orgânica com as desigualdades históricas entre os países e no interior destes.

As grandes conferências internacionais que trataram do problema da escassez de água no mundo ${ }^{3}$ deliberaram em favor da necessidade de gestão compartilhada dos recursos hídricos e da atribuição de valor econômico à água, apontadas como saída obrigatória para solucionar os problemas da escassez deste recurso e da regulação de seus usos (CANELON PERÉZ, 2004). O argumento da escassez e a estratégia de cobrar pelo seu uso são utilizados como instrumento disciplinar, visando produzir mudanças nos comportamentos dos usuários para atitudes de preservação e uso equilibrado, além de garantir a sustentabilidade financeira dos sistemas de gestão.

\section{A mercantilização da água é a} expressão inequívoca da expropriação no campo e da apropriação privada dos recursos naturais. É a manifestação da expansão

\section{imperialista sobre um bem}

\section{natural antes partilhado, o qual}

foi integrado à lógica da acumulação.

O capital financeiro se tornou protagonista desse processo, na medida em que influenciou diretamente a condução das proposições e das decisões importantes em matéria de água e assumiu posição reguladora ao integrar conselhos e delegações internacionais para discutir as estratégias na matéria. Assim, a constituição de um consenso em torno da escassez busca legitimar as saídas privatistas, cujo fim último é o escoamento de capitais para este novo campo de investimento - a exploração privada da água.

A mercantilização da água é a expressão inequívoca da expropriação no campo e da apropriação privada dos recursos naturais. É a manifestação da expansão imperialista sobre um bem natural antes partilhado, o qual foi integrado à lógica da acumulação. A usurpação das águas comuns ocorre, de maneira recorrente, com o uso intensivo da violência o que pode ser verificado no aumento substancial dos conflitos por água no Brasil, registrados pela Comissão Pastoral da Terra (CPT) - no período de 2002-2017 - mas também na articulação de um determinado consenso em torno da escassez para, então, apresentar a solução via privatização da água. Em síntese, o discurso da escassez foi criado e orientado na direção da lucratividade das grandes corporações multinacionais que defendem a água como mercadoria (FERREIRA; REBÊLO JÚNIOR, 2007).

Sendo a água um recurso natural imprescindível e insubstituível a todas as formas de vida, é também um negócio promissor para a expansão de capitais, posto que jamais haverá ausência de demanda. Ninguém pode prescindir de água, nem a tornar um elemento supérfluo no consumo diário, seja para o abastecimento humano e animal, seja nas cidades ou no campo como também nos processos produtivos que garantem a reprodução da vida.

As disputas por água no Nordeste brasileiro marcam o território desde sua ocupação. A busca pelos solos férteis, pelos brejos úmidos e pela apropriação dos recursos naturais estão na base de importantes conflitos entre os povos do campo e os representantes do capital, nos diferentes momentos históricos. Os conflitos são acirrados nos períodos de grandes estiagens, os quais exponenciam a articulação entre devastação da natureza e exploração do trabalho nas grandes propriedades. Apesar da propalada alternativa para a chamada crise hídrica, pela via da privatização e mercantilizarão das águas, as últimas décadas têm assistido o agravamento das desigualdades sociais no campo e o aumento significativo dos conflitos que envolvem a posse, a propriedade e os diversos usos da água pelas populações rurais. O acirramento dos conflitos no campo evidencia a relação de dependência entre os povos que ali vivem e a natureza, de um lado e os processos de expropriação nos espaços rurais, combinada à apropriação privada dos recursos naturais, de outro. Este processo ameaça diretamente as condições de vida e de trabalho das populações do campo: ribeirinhos, quilombolas, pescadores(as), 
indígenas e pequenos agricultores, as quais estabelecem seu metabolismo social em estreita dependência dos recursos naturais (FOSTER, 2005).

Estes conflitos, que vêm se alastrando pelo País, exibem as contradições da gestão ambiental pública, instituída pela Política Nacional do Meio Ambiente e pela Norma Constitucional vigente. No que se refere à água, a legislação aponta como dever do Estado a necessária regulação do seu uso comum, com vistas a disponibilizá-la para as presentes e futuras gerações, pois sem água não existe vida ${ }^{5}$.

Nossa apreciação acerca da literatura especializada, ainda que em breves linhas, remete à constatação de que a denominação conflitos socioambientais vem sendo aplicada a um conjunto de problemáticas que, em alguma medida, envolve a disputa pelos recursos ecossistêmicos, aí incluída a água. No entanto, quase sempre tomada em sentido genérico e descontextualizado, esta denominação tende a ofuscar determinações essenciais desses fenômenos, de forma que favoreçam análises supraclassistas e esvaziadas de mediações.

Se por um lado, a disseminação do conceito de conflitos socioambientais relaciona-se ao legítimo alargamento das pautas e agendas dos movimentos e das lutas sociais - expressão empírica do avanço da destrutividade ambiental e seu entrecruzamento com a questão urbana e agrária - por outro, a sua utilização descontextualizada das mediações essenciais que fundam a sociedade do capital acaba por esmaecer a natureza classista desses fenômenos, esvaziando seu potencial de crítica e de oposição ao mundo mercantil. Chama a atenção, neste caso, a presença de conceitos como: grupos sociais, atores sociais, agentes sociais para se referirem aos sujeitos em confronto, ao tempo em que são invisibilizadas as classes sociais, frações de classes, ideologias, dentre outros.

$\mathrm{O}$ artigo que ora se apresenta tem como objetivo refletir sobre os conflitos socioambientais por água na região Nordeste do País, problematizando-os à luz de suas determinações estruturais: a expansão do agronegócio e seus impactos sobre as populações do campo. Este resulta de reflexões que tiveram lugar a partir de uma ampla revisão bibliográfica, além da análise de documentos institucionais que versam sobre a temática. Assim, apreende-se que a apropriação privada de mananciais hídricos fígura como principal causa dos conflitos por água no Nordeste, o que nos leva a concluir que o acirramento dos conflitos socioambientais por água na região está diretamente vinculado à apropriação privada dos recursos naturais, especialmente a terra.

\section{Conflitos por água no campo e questão agrária no Brasil}

Os conflitos socioambientais vêm se intensificando no Brasil na última década, envolvendo tanto populações do campo como das cidades. O registro desse fenômeno pelos movimentos sociais, organizações não governamentais e redes de pesquisadores vem possibilitando importantes estudos acerca da natureza, extensão, desenvolvimento e dos sujeitos envolvidos nas disputas ${ }^{6}$. Projeto inédito da Universidade Autônoma de Barcelona, em parceria com organizações de justiça ambiental, mapeou conflitos socioambientais em todo mundo. No referido mapa ${ }^{7}$, o Brasil aparece em segundo lugar em número de disputas.

No tocante à sua natureza, os dados coletados no Brasil demonstram a ocorrência de conflitos por recursos distintos, tais como terra, água, atividade mineradora, vegetação, dentre outros. No tocante aos conflitos no campo, os relatórios da $\mathrm{CPT}^{8}$, que condensam anualmente os dados do País, destacam que terra, água e trabalho escravo estão entre os principais indicadores. No âmbito deste trabalho será dado particular destaque aos conflitos que envolvem a água, ou diretamente Aqueles em que este recurso se encontra no centro da contenda ${ }^{9}$. Tomamos como referência analítica a região Nordeste do Brasil, marcada pela ofensiva ideopolítica da denominada indústria da seca, a qual ancorou, historicamente, a reprodução da desigualdade social e a drenagem dos recursos públicos para as grandes obras hídricas, destinadas a favorecer, especialmente, o latifúndio.

Assim como no Brasil, a região Nordeste marca uma tendência de crescimento das disputas: em 2017 foram 63 conflitos, envolvendo 13.232 famílias (CENTRO DE DOCUMENTAÇÃO DOM TOMÁS BALDUINO - CPT, 2018), enquanto em 2016, foram registrados 42 conflitos, envolvendo 7.451 famílias (CENTRO DE DOCUMENTAÇÃO DOM TOMÁS BALDUINO - CPT, 2017) em todo o seu território. Em comparação com o cenário nacional, o Nordeste ocupa o segundo lugar no ranking do quantitativo de conflitos por ano e o terceiro quanto ao número de famílias envolvidas. Os conflitos no Nordeste envolvem, principalmente, usos e preservação, construção de barragens e açudes e apropriação privada da água. 
Tabela 1 - Conflitos por água no Nordeste (2012-2017)

\begin{tabular}{|c|c|c|c|c|c|c|c|c|c|c|c|c|}
\hline \multirow{3}{*}{ ESTADO } & \multicolumn{12}{|c|}{ ANO } \\
\hline & \multicolumn{2}{|c|}{2012} & \multicolumn{2}{|c|}{2013} & \multicolumn{2}{|c|}{2014} & \multicolumn{2}{|c|}{2015} & \multicolumn{2}{|c|}{2016} & \multicolumn{2}{|c|}{2017} \\
\hline & $\mathrm{C}^{*}$ & $\mathrm{FE}^{* *}$ & $\mathrm{C}^{*}$ & $\mathrm{FE}^{* *}$ & $\mathrm{C}^{*}$ & $\mathrm{FE}^{* *}$ & $\mathrm{C}^{*}$ & $\mathrm{FE}^{* *}$ & $\mathrm{C}^{*}$ & $\mathrm{FE}^{* *}$ & $\mathrm{C}^{*}$ & $\mathrm{FE}^{* *}$ \\
\hline Alagoas & - & - & 2 & 66 & 2 & 120 & 1 & 0 & - & - & 1 & 350 \\
\hline Bahia & 8 & 720 & 21 & 259 & 26 & 5819 & 27 & 2687 & 24 & 3851 & 56 & 10767 \\
\hline Ceará & 4 & 524 & 4 & 465 & 1 & 45 & 2 & 244 & 3 & 410 & - & - \\
\hline Maranhão & 8 & 610 & - & - & 4 & 25 & 5 & 0 & 8 & 1632 & - & - \\
\hline Paraíba & 2 & 1133 & 3 & 1300 & - & - & - & - & - & - & - & - \\
\hline Pernambuco & 5 & 493 & 5 & 892 & 8 & 3400 & 9 & 6110 & - & - & 6 & 2115 \\
\hline Piauí & 1 & 400 & - & - & - & - & 2 & 304 & 1 & 10 & - & - \\
\hline Rio Grande do Norte & - & - & 1 & 1200 & 1 & 1003 & - & - & 1 & 1003 & - & - \\
\hline Sergipe & - & - & 1 & 0 & - & - & - & - & 5 & 545 & - & - \\
\hline Total & 28 & 3880 & 37 & 4182 & 42 & 10412 & 46 & 9345 & 42 & 7451 & 63 & 13232 \\
\hline
\end{tabular}

Fonte: Elaboração própria a partir dos dados do Centro de Documentação Dom Tomás Balduíno-CPT(2013, 2014, 2015, 2016, 2017, 2018).

Notas: Sinal convencional utilizado:

- Dado numérico igual a zero não resultante de arredondamento.

${ }^{*} \mathrm{C}=$ Conflitos

$* * \mathrm{FE}=$ Famílias envolvidas

A Tabela 1 demonstra que em meia década (2012-2017) foram contabilizadas pela CPT 258 conflitos por água no Nordeste, envolvendo 48.502 famílias. Os números mais alarmantes se encontram na Bahia onde se concentram 162 conflitos e 24.103 famílias envolvidas. Pernambuco é o segundo Estado que lidera tanto em número de conflitos (33) como em famílias atingidas (13.010). Chama-nos a atenção os registros em Pernambuco: apesar de ser um Estado relativamente pequeno em área territorial, se comparado à Bahia, tem registrado conflitos importantes no que diz respeito à propriedade e aos usos da água no campo.

A situação do conflito ${ }^{10}$ é também um elemento importante a considerar. Considerando-se apenas o relatório com os dados referentes a 2017 , para analisar os elementos motivadores dos conflitos por água na região Nordeste, encontram-se os seguintes resultados: dos 63 conflitos registrados na região, dois referem-se ao não cumprimento de procedimentos legais; 14 dizem respeito à destruição e poluição de mananciais hídricos, e envolvem diretamente demandas de uso e preservação da água; e 47 dos conflitos denunciam a apropriação particular da água, que resulta na diminuição do acesso pela população atingida (CENTRO DE DOCUMENTAÇÃO DOM TOMÁS BALDUINO - CPT, 2018).

A forte incidência dos conflitos socioambientais envolvendo água no Nordeste brasileiro encontra-se marcada pela desigualdade de acesso, agravada pela irregularidade nas precipitações pluviométricas. No entanto, vale registrar a atuação dos entes públicos no tocante aos principais elementos motivadores dos conflitos.

$\mathrm{Na}$ atualidade, a subordinação da natureza ao capital no campo se expressa, diretamente, na expansão do agronegócio, responsável pela contaminação dos solos e dos alimentos, e produz os mais graves problemas de poluição das águas subterrâneas e superficiais de rios, lagos e açudes (RIGOTTO; AGUIAR, 2015). A água é um elemento tradicionalmente acessado como parte indivisível da propriedade da terra e, muito comumente, é apropriada junto ao território que ocupa; mas também as águas são apropriadas, indiretamente, quando rios são desviados, represas e diques são construídos, mananciais são utilizados privadamente ou ainda no caso da mercantilização das águas subterrâneas.

Também se trata de apropriação privada quando, em decorrência da atividade industrial ou agroindustrial, mananciais de águas são contaminados, impedindo o seu uso coletivo. Em todos esses casos, as águas passam a ser separadas de seus territórios e, ao sê-lo, cria-se um impacto que se estende para além das atividades originárias para as quais se destinam. Assim, o desvio de um rio implica seca e desertificação uma região antes 
irrigada etc. É nesse sentido que se afirma que o debate sobre a água no campo compõe a questão agrária no Brasil, pois o capital no campo não avança apenas sobre a propriedade da terra, mas também pelos caminhos das águas. É assim que o capital se move e se reproduz no campo, "[...] atrás das melhores manchas de terra e dos maiores volumes de água [...]” (MALVEZZI, 2007, p. 63).

$\mathrm{O}$ acesso às fontes de água segura no campo, bem como a posse ou propriedade da terra expõem as maiores contradições entre o capital privado e suas necessidades de acumulação por um lado, e por outro, os modos de vida dos pequenos(as) produtores(as) rurais, camponeses(as) e trabalhadores(as) assalariado(a)s. Por essa razão, a relação entre apropriação privada dos elementos da natureza e a acumulação de capital tem centralidade no debate da questão agrária.

Ao refletir sobre a questão agrária, Prado Junior (1979) revela as contradições da propriedade privada da terra e das relações de trabalho estabelecidas no campo. Assim, a relação que é estabelecida com a terra e demais recursos naturais indispensáveis à produção revela o conflito entre proprietários (para quem a terra é uma forma de negócio), e os produtores diretos (que tem na terra sua condição de sobrevivência). Apesar do evidente antagonismo, de forma muito recorrente, os interesses das classes dominantes são confundidos com os interesses gerais dos povos do campo. Como afirma o autor (PRADO JUNIOR, 1979, p. 32):

É nisso que consiste essencialmente a nossa questão agrária. E ela se resume nisto que a grande maioria da população rural brasileira, a sua quase totalidade, com exclusão unicamente de uma pequena minoria de grandes proprietários e fazendeiros, embora ligada à terra e obrigada a nela exercer sua atividade, tirando daí seu sustento, se encontra privada da livre disposição da mesma terra em quantidade que baste para lhe assegurar um nível adequado de subsistência. Vê-se assim forçada a exercer sua atividade em proveito dos empreendimentos agromercantis de iniciativa daquela mesma minoria privilegiada que detém o monopólio virtual da terra.

Sob hegemonia da finança mundializada, o sistema do capital aprofunda a subalternidade dos países periféricos a partir da exploração dos recursos naturais e da força de trabalho, apoiada por uma legislação flexível e favorável às necessidades da acumulação. Como resultado deste novo arranjo mundial, os países pobres ficaram encarregados dos custos ambientais, enquanto as questões relativas à contribuição desigual dos países no agravamento da destrutividade ambiental são desconsideradas (SILVA, 2015).

A partir do início dos anos de 1990, sob a hegemonia do projeto neoliberal, o Brasil recua da etapa de industrialização por substituição das importações (ISI) - na qual vivenciara a expansão do seu parque industrial - rumo à retomada da tradição (nunca de todo abandonada) de fornecedor de produtos de origem agrário-extrativista para o mercado global, aprofundando a sua condição de economia periférica e dependente. Neste sentido, consolida seu papel de provedor de recursos naturais e matérias primas brutas ou semi-faturadas para o mercado mundial a partir da década de 1990, em um processo denominado de reprimarização da economia, no contexto de dominância do capital financeiro (ARAÚJO; SILVA, 2015).

A divisão internacional do trabalho impõe o modelo agroexportador aos países periféricos, afetando as condições de disponibilidade hídrica para os usos prioritários, alterando o cenário das demandas por água no País e desconsiderando as diretrizes legais definidas pelos países envolvidos, como é o caso do Brasil. Assim, o Brasil torna-se um dos principais exportadores de produtos agropecuários, e em consequência, de água virtual (LAINÉ, 2012).

Vale ressaltar que o Brasil tem mantido e aprofundado, desde essa época, um modelo de desenvolvimento agrário-extrativista de exportação, que se expressa radicalmente no agronegócio, com a plena anuência e incentivo do Estado brasileiro. O agronegócio se apresenta, nesse contexto, como um modelo de produção rural marcado pela lógica produtivista e a eficiência econômica, que se distingue das formas tradicionais de ocupação do solo, especialmente do latifúndio improdutivo (LAINÉ, 2012). De acordo com a autora,

A forma de produção do agronegócio pode ser interpretada como a reinvenção da colônia, pois prioriza uma agricultura voltada ao mercado externo, que importa seus principais insumos, e cujos rendimentos beneficiam apenas uma minoria, promovendo a concentração da riqueza, a exclusão ou precarização da mão de obra no campo e a degradação ambiental. (LAINÉ, 2012, p. 333).

Essa minoria referida por Lainé (2012) são as grandes corporações transnacionais que, sob a justificativa do progresso e do desenvolvimento, têm orientado o padrão de acumulação de capital no campo, abrindo nichos de investimento nos países periféricos, na promoção de novos arranjos produtivos, na fragilização das regulações estatais quanto aos direitos trabalhistas, ambientais e fundiários. Enfim, impõem um modo de vida hegemônico e padronizado, que se apropria dos bens naturais, provoca alterações significativas nas dinâmicas 
e nos processos produtivos e não consideram a cultura e o saber dos povos originários, o que termina por gerar inúmeros conflitos socioambientais (RIGOTTO; AGUIAR, 2015).

Um aspecto importante a ser considerado é que a grande propriedade agropecuária, onde se expandem os cultivos do agronegócio, além da responsabilidade sobre a contaminação dos solos e dos alimentos, apresenta os mais graves problemas de poluição das águas subterrâneas e superficiais de rios, lagos e açudes (RIGOTTO; AGUIAR, 2015). Assim, não só pela disponibilidade de terras, mas também de águas, o Brasil se tornou um importante provedor de commodities para o mercado internacional. Por ter a maior disponibilidade hídrica do mundo (cerca de $12 \%$ das reservas mundiais), o Brasil também é um dos maiores exportadores de água virtual, o que interessa aos países centrais, na medida em que contorna a escassez quantitativa dos países importadores. Ao deslocar a produção agrícola de produtos primários, também são deslocadas a poluição dos mananciais hídricos, a contaminação dos solos e adoecimento dos trabalhadores que manuseiam, diretamente, os agrotóxicos, e assim, os custos insustentáveis da produção agroindustrial são pagos pela periferia do sistema.

Trata-se, assim, de afirmar que a água, assim como a terra, é um bem de natureza política e, portanto, pressupõe conflitos pela sua apropriação e controle (LAINÉ, 2012). Na agricultura camponesa, a água está diretamente ligada à produção de alimentos e, portanto, é um elemento vital para garantir a vida das pessoas que trabalham na terra (MARTINS, 1982). Por isso, as profundas alterações da natureza, produzidas pelo agronegócio que contaminam os solos, afetam a disponibilidade de águas, e interferem no clima, comprometem, diretamente, as condições de vida das populações rurais.

\section{O agronegócio e as expropriações: a contínua reprodução da desigualdade no campo}

A produção teórica sobre o meio rural já tem apontado a centralidade da terra e a continuada expropriação camponesa, marcada pela concentração fundiária e pela proletarização dos trabalhadores rurais como elementos fundantes da questão agrária no Brasil. No entanto, a água nesse contexto também expressa as contradições, conflitos e disputas no espaço agrário, seja pela apropriação de grandes volumes de água para a produção das commodities agrícolas ou pela contaminação dos mananciais, gerado pela utilização de agroquímicos para incrementar a produtividade agro-industrial.

Neste sentido, a expropriação e a apropriação privada dos recursos sociais destinados à produção são chaves heurísticas importantes para entender como a acumulação capitalista se particulariza no campo. Esse processo, que resulta na pauperização e proletarização camponesa, parte da separação objetiva dos produtores(as) rurais dos diferentes recursos e meios de trabalho, da concentração fundiária e da subordinação do trabalho às condições impostas pelo capital, dando forma aos processos já mencionados. Essas tendências, anteriormente descritas, se particularizam no Brasil por via do entrecruzamento de vários processos que complexificam ainda mais o cenário nacional: a expropriação de terras indígenas, a larga utilização do trabalho escravo e do incentivo ao extrativismo e o latifúndio, que foi e continua sendo um traço característico da inserção subordinada do País à acumulação de capital.

Os processos de expropriação estão presentes na apropriação e destruição da natureza e na sua completa transformação em mercadoria, evidenciando que estamos diante de novas formas de cercamento. A este respeito, Harvey (2005, p. 123) admite que:

A corporativização e a privatização de bens até agora públicos (como as universidades), para não mencionar a onda de privatizações (da água e de utilidades públicas de todo gênero) que tem varrido o mundo, indicam uma nova onda de 'expropriação das terras comuns'. Tal como no passado, o poder do Estado é com frequência usado para impor esses processos mesmo contrariando a vontade popular.

Essas novas expropriações se associam aos processos de supercapitalização, que representam os nichos de valorização mercantil abertos para dar escoamento lucrativo ao capital excedente. Esta categoria expressa o movimento tendencial do capitalismo contemporâneo de buscar novas formas de valorização a partir do investimento do capital excedente em novos setores (produtivos ou improdutivos), processo que tem como consequência a mercantilização e a privatização de bens comuns, dos recursos naturais e de direitos socialmente conquistados, que deixam de ser oferecidos como serviços públicos e passam a ser mediados pelo mercado (MANDEL, 1982). Nas palavras do autor:

Em última instância, todas essas tendências correspondem à característica básica do capitalismo tardio: o fenômeno da supercapitalização, ou capitais excedentes não investidos, acionados pela queda secular da taxa de lucros e acelerando a transição para o capitalismo monopolista. Enquanto o "capital" era relativa- 
mente escasso, concentrava-se normalmente na produção direta de mais-valia nos domínios tradicionais da produção de mercadorias. Mas se o capital gradualmente se acumula em quantidades cada vez maiores, e uma parcela considerável do capital social já não consegue nenhuma valorização, as novas massas de capital penetrarão cada vez mais em áreas não produtivas [...] (MANDEL, 1982, p. 272, grifo do autor).

No processo de supercapitalização, o capital ocioso é convertido em capital de serviços, ao mesmo tempo em que bens comuns e serviços que eram públicos e gratuitos são convertidos em mercadorias. Esta lógica cria necessidades inexistentes, controla bens naturais essenciais à vida, transformando-os em recursos privados, mercadoriza o tempo livre, o lazer, a ciência e a arte, enfim, amplifica a reprodução das relações capitalistas sobre todas as esferas da vida.

O papel do Estado é central no processo de liberação de ativos e na criação de novos campos de investimento para o capital, Os processos de supercapitalização incidem sobre os estatutos regulatórios do trabalho e do meio ambiente, permitindo ao Estado transformar bens comuns em propriedade pública estatal, para em seguida facilitar e possibilitar a exploração privada destes mesmos recursos.

Neste contexto, o processo de expropriação das águas no Brasil ocorre mediante uma obra de destacada engenhosidade política. Em nome de uma regulamentação jurídica e da consideração legal da água como direito público fundamental - ocorre um processo de estatização da água. Em princípio, este processo demarca um ganho significativo para o processo de democratização dos recursos naturais, posto que a água sai do campo privado, do direito civil e passa para a esfera pública, e assim faz convergir ações sistemáticas do poder público para os serviços de abastecimento de água e de saneamento básico. Teoricamente, é deslegitimada a propriedade privada da água na Constituinte de 1988, que vai vincular o recurso natural à ideia de bem comum e interesse público (GOMES; MIRANDA, 2013). A partir deste momento o Estado passa a definir os rumos das águas e a cuidar das políticas de sua gestão.

No entanto, a partir da apreensão das contradições históricas do atual processo de expropriações, é possível concluir que a consideração da água como questão pública e estatal foi determinante para a sua privatização e sua transformação em mercadoria. E neste processo, o Estado cumpre o papel de cancelar o direito de todos ao acesso livre e gratuito às águas, ao transformar o direito à água em uma questão pública, e ao mesmo tempo em que torna possível o acesso privado para quem por ela possa pagar, através do direito de outorga $^{11}$, o que consolida, definitivamente, a concepção da água como bem econômico (GOMES; MIRANDA, 2013). Assim, a água torna-se mercadoria em um contexto muito particular do capital, posto que este instrumento garante que a água do território nacional está disponível à exploração privada, mediante o pagamento pelo seu uso. E de acordo com as grandes corporações do capital hídrico internacional, isso só será garantido com os investimentos privados (PETRELLA, 2003).

Ao assegurar o efetivo direito de acesso à água pelo direito de outorga, a legislação em vigor resolve o problema dos conflitos por água, entregando-a a quem pode pagar por ela. Este processo implica duas tendências que se combinam: a privatização dos serviços de saneamento ${ }^{12}$; e, de outro modo, abre a possibilidade de privatização de importantes mananciais, de forma que o capital possa deles se utilizar - inclusive na produção - em detrimento das necessidades da maioria da população.

A conjuntura sucedânea ao golpe de 2016 aprofunda o contexto de crise institucional e política, momento em que a ofensiva do capital sobre os recursos naturais se intensifica, com as negociações em torno da privatização das águas, das reservas minerais e da biodiversidade, especialmente na Amazônia, dentre outros, de forma que os conflitos socioambientais tendem ao acirramento. No interior desta dinâmica irracional e voraz do capital, constatam-se retrocessos legais e efetivos com repercussões para as atuais e futuras gerações. Denúncias de negociatas, envolvendo o governo e grandes corporações internacionais, tendo como objeto grandes mananciais hídricos do país, foram formuladas pelo Fórum Alternativo Mundial da Água (FAMA) e ganharam espaço na imprensa, o que obrigou o governo a se posicionar sobre o tema, negando tais iniciativas (PARA..., 2018; PRIVATIZAÇÃO..., 2017).

No território brasileiro localizam-se 182 aquíferos, incluindo os dois maiores do planeta: o Aquífero Guarani e o Aquífero Grande Amazônia, este último com mais de $162.000 \mathrm{~km}^{3}$ de água. Aquífero Guarani é o mais conhecido e o segundo maior, com área total de 1,2 milhão de $\mathrm{km}^{2}$, sendo mais de dois terços desta em território brasileiro, além das áreas localizadas na Argentina, Uruguai e Paraguai. É considerado um dos mais importantes do ponto de vista do abastecimento da região, sobretudo para as futuras gerações (PARA..., 2018). Abaixo do Rio São Francisco, localiza-se, ainda, um terceiro aquífero brasileiro, também de suma importância por seu valor estratégico, o Aquífero Urucuia (ESTUDOS..., c2019). Trata-se de um rico manancial, motivo de cobiça do capital em tempos de mundialização financeira.

Desse modo, o Estado neoliberal é o agenciador central da destituição de direitos constituídos e de bens naturais, que são os principais alvos da abertura destes novos campos de acumulação (HARVEY, 2007). 
Portanto, a subalternização da natureza em relação aos interesses do capital, é explicada pela tríade expropriação-apropriação privada-mercadorização, que exprime a dinâmica própria da supercapitalização e a tendência do capital de mercantilizar tudo o que existe, em favor da acumulação. Podemos afirmar com os autores que "[...] a natureza do capitalismo é capitalizar a natureza". (AGUIAR; BASTOS, 2012, p. 87).

No campo da ofensiva ideopolítica, o capital não dá trégua. Segundo o Atlas do Agronegócio (FUNDAÇÃO HEINRICH BÖLL; FUNDAÇÃO ROSA LUXEMBURGO, 2018), no período de 2011 a 2018, a Bancada Ruralista no Congresso Nacional propôs 43 Projetos de Lei que ameaçam a demarcação de terras indígenas e quilombolas. $\mathrm{O}$ interesse maior do agronegócio é o acesso às terras que por direito pertencem às populações indígenas e quilombolas, dificultando a demarcação e o reconhecimento oficial. Buscam, assim, favorecer o arrendamento ou comercialização, abrindo a possibilidade para a implementação nos territórios de projetos de mineração, hidroenergia, infraestrutura etc.

O que vale destacar neste cenário mais amplo, que a um só tempo emoldura e manifesta as tendências da acumulação de capital no País no século XXI, é a sua natureza destrutiva, a qual promove intensos conflitos, distribuídos ao longo do território nacional. Embora pulverizados, por vezes com expressões localizadas (em outros casos se dotam de maior abrangência), fato é que as reações à degradação crescente dos bens naturais pelo capital, com destaque para a apropriação privada da água - diretamente patrocinada pelo Estado ou com a conivência deste - tem se intensificado; uma multiplicidade e diversidade de agendas se evidenciam, revelando métodos de luta por vezes surpreendentes: ocupações de agências estatais e privadas, interrupções de vias públicas, manifestações e denúncias aos meios de comunicação, aos organismos internacionais, dentre outros. São pescadores, agricultores familiares, indígenas, quilombolas, dentre muitos, cujo traço comum é a dependência dos bens naturais para assegurar os meios de sua reprodução. Estes processos de luta sinalizam as contradições do padrão de acumulação, fundamentalmente marcado pela expansão econômica, pela reprodução da pauperização e pela degradação das condições de vida dos trabalhadores.

\section{Considerações finais}

O quadro anteriormente exposto é revelador de que as restrições no acesso à água no Nordeste brasileiro, como de resto em todo o País, longe de restringir-se à escassez, como propala o discurso hegemônico, encontra-se diretamente vinculado à apropriação privada da terra e dos demais recursos naturais, como parte dos processos de contínua expropriação, levada a efeito pela expansão do capital no campo. As grandes obras de infraestrutura, a pecuária intensiva, a fruticultura irrigada, especialmente voltada para a exportação, incidem sobre as águas disponíveis, acentuando as desigualdades no acesso, penalizando, sobretudo, as populações tradicionais e trabalhadores do campo.

Em síntese, a permanência e o aprofundamento da questão agrária no Brasil determinam o aumento dos conflitos por água no campo. Daí ser impossível pensar os conflitos por água no campo sem considerar a questão da propriedade da terra, partindo de uma concepção ampliada da questão agrária, que inclui a terra, a água, as culturas alimentares e os recursos minerais. Nesse sentido, os conflitos por água no Nordeste situamse no interior do movimento das classes em conflito em torno da apropriação dos recursos indispensáveis à sua reprodução. É a luta de classes que se atualiza, manifestando a complexificação da dinâmica do capital em tempos de mundialização financeira.

\section{Referências}

AGUIAR, J. V.; BASTOS, N. Uma reflexão teórica sobre as relações entre natureza e capitalismo. Revista Katálysis, Florianópolis, v. 15, n. 1, p. 84-94, jan./jun. 2012.

ARAÚJO, N. M. S.; SILVA, M. G. Desenvolvimento brasileiro e hiperexploração dos recursos naturais: avanço do capital e regressão da ação reguladora do Estado. In: SANTOS, J. S.; VASCONCELOS, M. C. A.; CRUZ, M. H. S.; ARAÚJO, N. M. S. (org.). Reconfiguração do Estado e suas expressões na política social brasileira. São Cristóvão: Editora da UFS, 2015. p. 55-82.

BRASIL. Lei $n^{\circ}$ 9.433, de 8 de janeiro de 1997. Institui a Política Nacional de Recursos Hídricos, cria o Sistema Nacional de Gerenciamento de Recursos Hídricos, regulamenta o inciso XIX do art. 21 da Constituição Federal, e altera o art. $1^{\circ}$ da Lei no 8.001 , de 13 de março de 1990, que modificou a Lei no 7.990, de 28 de dezembro de 1989. Brasília, DF: Presidência da República, [2019]. Disponível em: http:/ /www.planalto.gov.br/ccivil_03/LEIS/L9433.htm. Acesso em: 29 abr. 2019.

CANELÓN PERÉZ, J. E. A gestão de água no Vale de Quíbor: uma análise psicossocial de uma forma tradicional de manejo e um bem comum. 2004. Tese (Doutorado em Psicologia Social) - Programa de Pós-Graduação em Psicologia Social, Pontifícia Universidade Católica de São Paulo, São Paulo, 2004. 
CENTRO DE DOCUMENTAÇÃO DOM TOMÁS BALDUINO - CPT. Conflitos no Campo Brasil 2012. Goiânia: CPT Nacional, 2013. Disponível em: https://cptnacional.org.br/component/jdownloads/send/41-conflitos-no-campo-brasil-publicacao/316-conflitosno-campo-brasil-2012. Acesso em: 29 abr. 2019.

CENTRO DE DOCUMENTAÇÃO DOM TOMÁS BALDUINO - CPT. Conflitos no Campo Brasil 2013. Goiânia: CPT Nacional, 2014. Disponível em: https://cptnacional.org.br/component/jdownloads/send/41-conflitos-no-campo-brasil-publicacao/344-conflitosno-campo-brasil-2013. Acesso em: 29 abr. 2019.

CENTRO DE DOCUMENTAÇÃO DOM TOMÁS BALDUINO - CPT. Conflitos no Campo Brasil 2014. Goiânia: CPT Nacional, 2015. Disponível em: https://www.cptnacional.org.br/component/jdownloads/send/41-conflitos-no-campo-brasil-publicacao/2392conflitos-no-campo-brasil-2014. Acesso em: 29 abr. 2019.

CENTRO DE DOCUMENTAÇÃO DOM TOMÁS BALDUINO - CPT. Conflitos no Campo Brasil 2015. Goiânia: CPT Nacional, 2016. Disponível em: https://www.cptnacional.org.br/component/jdownloads/send/41-conflitos-no-campo-brasil-publicacao/14019conflitos-no-campo-brasil-2015. Acesso em: 29 abr. 2019.

CENTRO DE DOCUMENTAÇÃO DOM TOMÁS BALDUINO - CPT. Conflitos no Campo Brasil 2016. Goiânia: CPT Nacional, 2017. Disponível em: https://www.cptnacional.org.br/component/jdownloads/send/41-conflitos-no-campo-brasil-publicacao/14061conflitos-no-campo-brasil-2016. Acesso em: 29 abr. 2019.

CENTRO DE DOCUMENTAÇÃO DOM TOMÁS BALDUINO - CPT. Conflitos no Campo Brasil 2017. Goiânia: CPT Nacional, 2018. Disponível em: https://www.cptnacional.org.br/component/jdownloads/send/41-conflitos-no-campo-brasil-publicacao/14110conflitos-no-campo-brasil-2017-web. Acesso em: 29 abr. 2019.

ESTUDOS hidrológicos e hidrogeológicos integrados na região do Aquífero Urucuia. CPRM. Brasília, DF, c2019. Disponível em: http:/ /www.cprm.gov.br/publique/Hidrologia/Projetos/Estudos-Hidrologicos-e-Hidrogeologicos-Integrados-na-Regiao-do-Aquifero-Urucuia5208.html. Acesso em: 29 abr. 2019.

FERREIRA, M. R.; REBÊLO JÚNIOR, M. As oligarquias da água e a mercantilização da água doce: um processo de conquistas do capital. Economia \& Pesquisa, Araçatuba, v. 9, n. 9, p. 54-77, ago. 2007.

FOSTER, J. B. A ecologia de Marx: materialismo e natureza. Rio de Janeiro: Civilização Brasileira, 2005.

FUNDAÇÃO HEINRICH BÖLL; FUNDAÇÃO ROSA LUXEMBURGO. Altas do agronegócio: fatos e números sobre as corporações que controlam o que comemos. Rio de Janeiro: Fundação Heinrich Böll, 2018. Disponível em: https://br.boell.org/sites/default/files/ atlas_agro_final_06-09.pdf. Acesso em: 29 abr. 2019.

GOMES, R. A.; MIRANDA, R. de S. Dinâmicas agrícolas, estratégias econômicas e pobreza rural no Nordeste do Brasil: especificidades regionais nos casos da cana-de-açúcar, da fruticultura irrigada e da soja. In: MIRANDA, C.; TIBURCIO, B. (org.). A nova cara da pobreza rural: desenvolvimento e a questão regional. Brasília: Instituto Interamericano de Cooperação para a Agricultura, 2013. (Série Desenvolvimento Rural Sustentável, v. 17). p. 183-215.

HARVEY, D. Neoliberalismo como destruição criativa. InterfacEHS - Revista de Saúde, Meio Ambiente e Sustentabilidade, São Paulo, v. 2, n. 4, ago. 2007.

HARVEY, D. O novo imperialismo. 2. ed. São Paulo: Loyola, 2005.

LAINÉ, P. C. V. Agronegócio, água virtual e segurança socioambiental. In: GEHLEN, V. R. F.; LAINÉ, P. C. V. (org.). Costurando com fios invisiveis: a fragmentação do território rural. Recife: Editora Universitária UFPE, 2012. p. 329-342.

MALVEZZI, R. Semi-árido: uma visão holística. Brasília: Conselho Federal de Engenharia, Arquitetura e Agronomia, 2007.

MANDEL, E. O capitalismo tardio. São Paulo: Abril Cultural, 1982.

MARTINS, J. de S. Expropriação e violência: a questão política no campo. 2. ed. São Paulo: Hucitec, 1982.

NÚCLEO ECOLOGIAS, EPISTEMOLOGIAS E PROMOÇÃO EMANCIPATÓRIA DA SAÚDE; ESCOLA NACIONAL DE SAÚDE PÚBLICA SERGIO AROUCA; FUNDAÇÃO OSWALDO CRUZ. Mapa de conflitos envolvendo injustiça ambiental e saúde no Brasil. [Rio de Janeiro: ENSP, 2019]. Disponível em: http://mapadeconflitos.ensp.fiocruz.br/. Acesso em: 29 abr. 2019.

PARA que serve um aquífero - e o que o governo pode fazer com eles? G1. Rio de Janeiro, 11 mar. 2018. Disponível em: https://g1.globo.com/natureza/noticia/para-que-serve-um-aquifero-e-o-que-o-governo-pode-fazer-com-eles.ghtml. Acesso em: 29 abr. 2019.

PETRELLA, R. A conquista da água. Cadernos Diplô - Le Monde Diplomatique, São Paulo, n. 3, p. 16-17, 2003.

PRADO JUNIOR, C. A questão agrária no Brasil. 2. ed. São Paulo: Brasiliense, 1979.

PRIVATIZAÇÃO do Aquífero Guarani: nossa maior reserva de água será da Coca-Cola ou Nestlé. Fórum Alternativo Mundial da Água. São Paulo, 14 jul. 2017. Disponível em: http://www.fenae.org.br/portal/fama-2018/noticias/privatizacao-do-aquifero-guarani-nossamaior-reserva-de-agua-sera-da-coca-cola-ou-nestle.htm. Acesso em: 29 abr. 2019.

RIGOTTO, R. M.; AGUIAR, A. C. P. Modelo produtivo do agronegócio, agrotóxicos e saúde humana. In: MITIDIERO JÚNIOR, M. A.; GARCIA, M. F.; VIANA, P. C. G. (org.). A questão agrária no século XXI: escalas, dinâmicas e conflitos territoriais. São Paulo: Outras Expressões, 2015. p. 225-250.

SILVA, M. das G. Sustentabilidade socioambiental e a retórica neodesenvolvimentista: apontamentos sobre meio ambiente e saúde no Brasil. Serviço Social \& Sociedade, São Paulo, n. 123, p. 428-446, jul./set. 2015.

SILVEIRA, S. M. B. A geopolítica da sede no Brasil: um estudo sobre a água e pobreza no campo. 2017. Tese (Doutorado em Serviço Social) - Programa de Pós-Graduação em Serviço Social, Universidade Federal de Pernambuco, Recife, 2017. 
TEMPER, L.; DEL BENE, D.; MARTINEZ-ALIER, J. Mapping the frontiers and front lines of global environmental justice: the EJAtlas. Journal of Political Ecology, Tucson, v. 22, n. 1, p. 255-287, 2015.

\section{Notas}

1 Este artigoé parte das reflexões e sínteses que foram resultado da elaboração da tese de doutorado $A$ Geopolítica da Sede no Brasil: um estudo sobre água e pobreza no campo, defendida em 2017 no Programa de Pós-Graduação em Serviço Social da Universidade Federal de Pernambuco(UFPE), de autoria de Sandra Maria Batista Silveira e orientada por Maria das Graças e Silva (SILVEIRA, 2017).

2 Neste trabalho estamos nos referindo à questão da água como um conceito que expressa uma problemática socioambiental que emerge na segunda metade do século XX, quando as discussões em torno da finitude e das ameaças de escassez quantitativa e qualitativa de água no mundo são tomadas como objeto da razão humana e da ação das classes, e põe em evidência as contradições no acesso e nos usos da água no campo e nas cidades, e desafiam o Estado na elaboração de respostas efetivas quanto ao suprimento de água para as demandas múltiplas e o saneamento básico.

3 Em 2002, na Conferência das Nações Unidas sobre o Financiamento do Desenvolvimento, realizada em Monterrey, México, constitui um marco importante deste debate. Nesta, foi apontada a importância de priorizar o financiamento privado para reduzir pela metade o número de pessoas que não têm acesso à água potável no mundo (PETRELLA, 2003). Estava consolidada a capitalização da água, com anuência do Estado. "Submetida à lógica capitalista, a água se torna cada dia mais um serviço privado, cuja gestão se concentra nas mãos de grandes empresas transnacionais, apoiadas em princípios estabelecidos pelo Banco Mundial e pelas negociações da OMC [Organização Mundial do Comércio]" (PETRELLA, 2003, p. 16).

4 Os conflitos por água no campo são registrados anualmente pela Comissão Pastoral da Terra. Em 2017 registrou-se o maior número de conflitos por água desde 2002.

5 A Lei n. ${ }^{\circ} 9.433 / 97$ dispõe que a gestão de recursos hídricos deve sempre proporcionar o uso múltiplo das águas (art. 1º, inc. IV), porém, em situações de escassez, o uso prioritário dos recursos hídricos é o consumo humano e a dessedentação dos animais (art. $1^{\circ}$, inc. III) (BRASIL, [2019]). O primeiro é a regra, o segundo a exceção.

6 Podemos citar como iniciativas relevantes o Mapa de Conflitos Envolvendo Injustiça Ambiental e Saúde no Brasil (NÚCLEO ECOLOGIAS, EPISTEMOLOGIAS E PROMOÇÃO EMANCIPATÓRIA DA SAÚDE; ESCOLA NACIONAL DE SAÚDE PÚBLICA SERGIO AROUCA; FUNDAÇÃOOSWALDOCRUZ, [2019]), organizado pela Fiocruzem parceria com universidades e organizações não governamentais e os relatórios Conflitos no Campo Brasil, produzidos anualmente pelo Centro de Documentação Dom Tomás Balduíno - CPT.

7 Mapa do Environmental Justice Atlas (TEMPER; DEL BENE; MARTINEZ-ALIER, 2015).

8 Relatórios publicados anualmente pelo Centro de Documentação Dom Tomás Balduíno - CPT desde 1985. Os relatórios encontram-se disponíveis em https://www.cptnacional.org.br/index.php/publicacoes-2/conflitos-no-campo-brasil.

9 Destaque-se que desde 2002, o setor de comunicação da CPT Nacional incluiu em seus relatórios de conflitos no campo os conflitos por água.

10 Termo utilizado pela CPT para designar as circunstâncias ou elementos motivadores dos conflitos.

11 É o ato administrativo mediante o qual o poder público outorgante (União, Estado ou Distrito Federal) faculta ao outorgado (requerente) o direito de uso de recursos hídricos, por prazo determinado, nos termos e nas condições expressas no respectivo ato. O ato administrativo é publicado no Diário Oficial da União, no caso da Agência Nacional de Águas (ANA), ou nos Diários Oficiais dos Estados ou do Distrito Federal. A outorga é o instrumento pelo qual a ANA faz o controle quantitativo e qualitativo dos usos da água. Esse controle é necessário para evitar conflitos entre usuários de recursos hídricos e para assegurar-lhes o efetivo direito de acesso à água.

12 Os interesses do capital privado tornaram-se prioritários nos serviços relacionados à água, o que gerou um desencontro entre as necessidades sociais de infraestrutura e as prioridades de acumulação de riquezas e expansão de lucros. A proposta é privatizar o conjunto dos serviços (captação, purificação, distribuição, conservação e tratamento) sob o argumento de combater eficazmente a escassez, garantir a gestão racional dos recursos, reduzir o desperdício e a contaminação dos aquíferos.

\section{Sandra Maria Batista Silveira}

sanmaria@hotmail.com

Doutorado em Serviço Social pela Universidade Federal de Pernambuco (UFPE)

Professora do Departamento de Serviço Social da Universidade Federal de Pernambuco (UFPE)

\section{Maria das Graças e Silva}

gracita.pe@gmail.com

Doutorado em Serviço Social pela Universidade Federal de Pernambuco (UFPE)

Professora do Departamento de Serviço Social e do Programa de Pós-Graduação em Serviço Social da Universidade Federal de Pernambuco (UFPE) 


\section{UFPE}

Centro de Ciências Sociais Aplicadas

Av. dos Economistas, s/n - Cidade Universitária

Recife - Pernambuco - Brasil

CEP: 52.000-000

\section{Agência financiadora}

Não se aplica.

Aprovação por Comitê de Ética e consentimento para participação

Não se aplica.

\section{Contribuições dos autores}

As autoras contribuíram igualmente para a realização e desenvolvimento deste artigo. A pesquisa é oriunda da tese de doutorado $A$ Geopolítica da Sede no Brasil: um estudo sobre água e pobreza no campo, de autoria de Sandra Maria Batista Silveira e orientada por Maria das Graças e Silva. A sistematização, análises e considerações sobre o tema são elaborações de ambas as autoras.

\section{Consentimento para publicação}

Não se aplica.

\section{Conflito de interesses}

Não há conflito de interesses. 